\title{
Educação Profissionalizante: Um Instrumento Para Emancipação Ou Alienação?
}

\author{
Antonia Angela de Limal ; Raimunda Tânia Pinheiro de Oliveira ${ }^{2}$
}

\begin{abstract}
Resumo: As relações desencadeadas pelo modelo de produção atual desvelam-se nos mais diversos setores da sociedade: no âmbito do trabalho e nas suas representações; no campo educacional como um todo e em seu recorte dos programas profissionalizante, além do quadro que se impõe ao Serviço Social inserido nesse cenário: Objetivando investigar como a educação é utilizada enquanto mecanismo para a manutenção do capital, é que a pesquisa se debruça sob o tema proposto o processo de precarização da educação em detrimento da manutenção do capital. A pesquisa de caráter qualitativa utilizou o estudo bibliográfico, reflexão dos rebatimentos desse contexto para a sociedade e a possível reversão do quadro posto e imposto pela ordem dominante.
\end{abstract}

Palavras-chave: Trabalho. Programas Profissionalizante. Educação.

\section{Vocational Education: an Instrument for Emancipation or Alienation?}

\begin{abstract}
The relations unleashed by the current production model are revealed in the most diverse sectors of society: in the scope of work and in their representations; In the educational field as a whole and in its cut of the vocational programs, in addition to the framework imposed on the Social Service inserted in this scenario: In order to investigate how education is used as a mechanism for the maintenance of capital, the research focuses on the Proposes the process of precariousness of education over the maintenance of capital. The qualitative research used the bibliographic study, reflection of the refutations of this context for the society and the possible reversion of the picture put and imposed by the dominant order.
\end{abstract}

Keywords: Work. Vocational Programs. Education.

\footnotetext{
${ }^{1}$ Assistente Social. Mestranda em Educaçao pela Anne Sulyvann University. E-mail: angelaxavieroliveira@ hotmail.com.

${ }^{2}$ Bióloga- Mestra pela Universidade Federal do Ceará. Vivência no ensino da Biologia Geral, com ênfase em Microbiologia, Administração Educacional e Métodos e Técnicas de Ensino. E-mail: t.biologa@gmail.com.
} 
Id on Line Revista Multidisciplinar e de Psicologia

Id on Line Multidisciplinary and Psycology Journal

\section{Educação como instrumento de adestramento da classe trabalhadora}

A educação é considerada o campo essencial para a dimensão da vida social, e o Estado se apropria da produção e repercussão da mesma, para dominar e controlar o que se é produzido e reproduzido nos âmbitos educacionais, ao perceber a educação como algo estratégico. Utilizando-se da coerção e do poder persuasivo da cultura hegemônica, transformando-a em senso comum, claramente, a escola se torna instrumento de propagação de valores da sociedade burguesa, aniquilando a cultura diversificada e o saber popular.

A industrialização brasileira que surge através de influências estrangeiras e foi caracterizada como tardia, serviu para suprir as necessidades locais. Ao curso do tempo, vem e modificando e se aperfeiçoando, de acordo, com as políticas sócio-econômicas. Fazendo com o que a industrialização percorra um caminho regido pelo capital. Sendo visto como relevante pontuar as políticas públicas para a juventude em tempos hodiernos, para traçara trajetória do percurso de conquistas de direitos pela criança e adolescente, para isso, necessita-se pontuar o tempo das transformações.

O trabalho propõe apresentar algumas reflexões referentes aos programas profissionalizantes do governo e os seus rebatimentos para as políticas públicas no contexto capitalista em consonância como papel do assistente social inserido nessa política enquanto executor e propositor de tais programas que regem e organizam o âmbito de produção e desenvolvimento. Com isso, podemos analisar que o governo propõe programas de desenvolvimento de trabalho, para a sua própria sustentação.

Diante do processo de profundas transformações ocorridas na educação na educação e na sociedade, durante o período compreendido entre 1500, aos dias atuais e que vieram refletir diretamente na estrutura familiar com rebatimentos na função da escola na pós-modernidade em que os transformações culturais, sociais, políticos, econômicos fazem surgir os novas demandas inerentes ao cotidiano escolar.

Com o objetivo de promover um melhor entendimento sobre a realidade do serviço social na educação brasileira, faz-se necessário discorrer brevemente sobre o seu histórico, especialmente na Política de Educação por se tratar também de espaços contraditórios que expressam as lutas de classes, em um determinado momento histórico se legitimam historicamente. 
Id on Line Revista Multidisciplinar e de Psicologia

Id on Line Multidisciplinary and Psycology Journal

De acordo com Almeida (2005).

[...] a política de educação pode ser concebida também como expressão da própria questão social na medida em que representa o resultado das lutas sociais travadas pelo reconhecimento da educação pública como direito social [...] (ALMEIDA, 2005 apud SILVA 2012, p.35).

Destaca-se aqui o fato da política educacional brasileira não ter se constituído até o momento em um direito social efetivo e universal. Onde apesar de ter sido defendida desde o início do século XX, sua efetivação sempre esteve marcada pela exclusão. É no marco desta trajetória que tenta compreender a inserção do Assistente Social na Educação relacionando seu processo histórico e sua efetivação dentro da política educacional.

\section{A inserção do assistente social na educação na educação.}

O Serviço Social é uma profissão regulamentada no Brasil pela Lei no . 3252/1957, posteriormente revogada pela Lei $\mathrm{n}^{\circ}$. 8.662/1993, onde as suas primeiras escolas surgiram no país na década de 30, ligada as fundações católicas, em que a igreja assumia até então as lutas relativas as questões sociais.

Neste período, o Assistente Social era condicionado a atuar não somente nas demandas inerentes ao Estado, como também, nas organizações ligadas á Igreja Católica ambos perpassadas pelo viés do assistencialismo, fundamentado pelo caráter de ajuda e caridade.

Somente após as transformações ocorridas na sociedade e com o avanço das ciências humanos-sociais e com a introdução de uma visão social nas demais profissões é que a situação da profissão viria a se modificar. Havendo crescimento e prestigio da considerada nova profissão. Neste contexto, os Assistentes Sociais passa a ser cada vez mais absorvidos pelo mercado de trabalho público e particular. Que este profissional não estava sendo requisitado somente na área assistencial, porém novas demandas ligadas á saúde, habitação, educação, entre outros, como também o seu engajamento nos movimentos sociais e na luta pelo proletariado.

Para uma melhor compreensão, abordaremos a inserção do Serviço Social nas escolas privadas e/ ou filantrópicas e nas escolas públicas. A inserção do Serviço Social nas escolas privadas e /ou filantrópicas vem sendo impulsionada por meio da implantação de monitoramento, avaliação e coordenação de projetos sociais, os quais possam atender ás 
Id on Line Revista Multidisciplinar e de Psicologia

Id on Line Multidisciplinary and Psycology Journal

demandas inerentes ao público escolar. Uma vez que o Assistente Social tem sido requisitado também nesta realidade escolar para a realização de avaliação socioeconômica, a fim de concessão de gratuidade com bolsas de estudos, conforme dispõe a Lei de Regulamentação da profissão, lei nº. 8.662/93.

Segundo Silva (2012) e entendendo a escola como um dos espaços de atuação do profissional, não podemos compreender que o trabalho do Assistente Social deve ser reduzir a fenômenos que recaiam sobre os estudantes da escola, mas que deve contemplar a comunidade escolar, compreendida pelos professores, servidores, familiares, estudantes e a comunidade no entorno da escola.

Ao sinalizar a inserção do Serviço Social na Escola Pública, atualmente encontramos apenas a criação de setores, departamentos, diretorias e ou coordenações junto a Secretarias Municipais de Educação ou a Universidades Públicas e Privadas, que desenvolvem projetos e atendimento com vistas ao atendimento das necessidades do aluno e da família na realidade escolar.

Podemos encontrar inúmeros Projetos de Lei que preveem a inserção do serviço social nas escolas públicas municipais e estaduais mediante concurso público, designado para a função de Assistente Social.

Desta forma, considera-se o Assistente Social, profissional de apoio á educação, profissional que atua em prol da integralidade do atendimento prestado ao aluno no contexto escolar, estando em consonância com a LDB (1996), que afirma:

Art. $2^{\circ}$. A educação dever da família e do Estado, inspirado nos princípios de liberdade e nos ideias de solidariedade humana, tem por finalidade o pleno desenvolvimento do educando, seu preparo para o exercício da cidadania e sua qualificação para o trabalho (BRASIL, 1996, p.100).

Percebe-se que a atuação do Assistente Social na Educação volta-se o alunado, seu bemestar, a garantia de acesso aos serviços oferecidos e a família. A inserção do Assistente Social na Educação constitui-se como ferramenta para a garantia do exercício da cidadania do aluno, que passa a refletir na família, através de atendimentos individualizados como também a promoção da democracia através da abertura de espaços de participação e envolvimento na realidade escola.

Com a articulação de grupos e comunidade, este profissional pode, como trabalhador social e cidadão, transformador a escola num espaço de debate viabilizando meios de 
Id on Line Revista Multidisciplinar e de Psicologia

Id on Line Multidisciplinary and Psycology Journal

participação que permitam á comunidade incentivar, decidir, fiscalizar e aplicar as políticas públicas.

Conforme Silva (2012) o Assistente Social na educação poderá atuar com todos os membros da comunidade escolar e para que ganhe visibilidade, aqui destaca-se na política de educação é necessário que este envolve e possibilitem em sua execução o despertar da capacidade crítica, criativa, propositivo e ainda um processo reflexivo que envolve a vida social, e das condições de vida que envolvem a sociedade.

\section{O Serviço Social na contribuição da emancipação do ser social}

No Brasil as políticas sociais estão relacionadas diretamente as condições vivenciadas pelo país em diversos níveis econômicos, político e social (PIANA, 2009, p.21). Caracterizadas hoje, mais como, concessões a classe trabalhadora, do que de fato conquista ordenada pela mesma. Como aponta Faleiros (1991), sobre as múltiplas faces da política social.

As políticas sociais ora são vistas como mecanismos de manutenção da força de trabalho, ora como arranjos do bloco governante, ora como doação dos ditos dominantes, ora como instrumento de garantia do aumento de riqueza dos direitos do cidadão (FALEIROS, p, 8, 1991).

Nesse bojo, o processo de elucidação da função do Serviço Social é contínuo, que a profissão é atingida pelos acontecimentos históricos e socioeconômicos desembocando um processo dinâmico e dialético. Logo, é essencial que se coloque pela prática os princípios éticos políticos da profissão de Serviço Social, principalmente sobre a socialização das informações em todos os espaços e oportunidades esclarecerem para todos e todas as funções e objetivos buscando sempre a consonância com os outros profissionais.

Levar o trabalho com seriedade respeito ás diretrizes e princípios do profissional, abarcando o perfil do público aproximar das questões que rodeiam os usuários, ressaltando o espírito investigativo conhecendo a política e objetivos da instituição são primordiais para a intervenção crítica, competente e combativa. Resvala-se diante do trabalho do assistente social inserido na política social nesses eixos que se acoplam dialeticamente na intervenção do assistente social que se propõe a uma atuação de caráter sociopolítico, crítico e interventivo. 
Em primeira instância deve-se aclarar a dimensão educativa e pedagógica do serviço social, que é inerente a profissão em todas as instâncias de intervenção, endereçada pelo princípio de desmistificar e despir a realidade expressa da exploração do modelo de organização social e econômica vigente, mobilizando um processo reflexivo que abarca uma percepção da tríade dialética: universalidade, singularidade e particularidade, através da racionalidade, propiciando a politização e análise crítica diante de numerosas realidades.

O processo educativo é exercido como instrumento para ampliação de direitos, quando se concebe que as ações incisivas para transformação das diversas refrações da questão social se darão em conjunto com a população, ou seja, com a sociedade civil organizada, e para isso, a mesma precisa estar alimentada de informação, a partir, de uma ação global de cunho educativo para possibilitar uma ação revolucionária.

A dimensão socioeducativa do serviço social é viabilizada através dos vínculos estabelecidos aos serviços estrategicamente prestados, por entre as políticas públicas que responde uma necessidade de subsistência do trabalhador, além disso, se coloca do mesmo lado da trincheira dos interesses da classe trabalhadora na luta e resistência a imposição da ordem do capital. Com o intuito, de deslindar o sentido da função educativa dos assistentes sociais, Maciel (2000, p.144), expõe:

A função dos assistentes sociais integra o amplo processo de elaboração de uma ideologia própria desenvolvido por essas classes, como elemento constitutivo de uma nova cultura. Supõe compromisso político consciente com o projeto societário das classes subalternas e competência teórica, metodológica e política para a identificação e apropriação das reais possibilidades postas pelo movimento social para o redimensionamento da prática profissional no horizonte da luta pela emancipação das referidas classes.

O exercício da dimensão pedagógica do assistente social permite uma aproximação com o usuário, na perspectiva que o mesmo permite ser afetado, proporcionando uma intimidade e aprofundamento de percepção/leitura de mundo por parte do usuário desenvolvendo um pensamento crítico, favorecendo a organização e mobilização, fortalecendo e viabilizando o enfrentamento coletivo das classes atendidas a utilizarem a luta como estratégia de superação desse modelo exploratório e injusto.

Para isso, exige-se do profissional de Serviço Social que o mesmo esteja devidamente habilitado a utilizar a dimensão técnica-operativa, ou seja, o saber fazer para manusear devidamente os instrumentos e técnicas; a dimensão ética-política, se apropriando dos 
Id on Line Revista Multidisciplinar e de Psicologia

Id on Line Multidisciplinary and Psycology Journal

princípios profissionais, além de exercer sua capacidade de questionar de maneira crítica e reflexiva sobre o imediato e por fim, mais, não menos importante, a dimensão teóricametodológica, que consiste no exercício de debruçar-se sobre a teoria, a disposição da apropriação do saber do conhecimento teórico.

Como o Serviço Social se constrói e reconstrói na dinâmica contraditória das políticas sociais, aponta-se portanto, a relevância do profissional de Serviço Social construir e acompanhar minuciosamente as políticas instauradas, com a responsabilidade do teor crítico e combativo na elaboração aplicação e principalmente no compromisso da luta cotidiana pela garantia de direitos como estratégia de solidificação da classe trabalhadora, indicando sempre pela emancipação do sujeito.

O capitalismo com suas várias manobras prega-se uma perspectivas educacional flexível e dinâmica para o alcance das demandas da inserção produtiva, sendo assim, no ensino técnico são postos desafios no caminho que se direciona a desconstrução da ideologia imperialista que o capital embute, o profissional de Serviço Social, por meio de suas diretrizes iria incidir junto a essa classe subalternizada, exercendo criticamente suas designações profissionais para a transformação societária, na construção de sujeitos políticos capazes de interpretar a sociedade em que estão obrigatoriamente imersos, nas suas reais objetivações e a sociedade em que estão obrigatoriamente imersos, nos suas reais objetivações e disfunções.

O Serviço Social se desenha nesse cenário, não como uma pseudo-representação social nem tampouco como justiça social, assim como diz GUERRA (2007), mas sim como mecanismo capaz de viabilizar um aprofundamento ao debate acerca da difusão do conhecimento como direito, na preocupação com o ensino profissional, por um significar grande desígnio do capitalismo a fim de consolidação dos seus ideais.

Enquanto a Educação for entendida como uma política social, e esse âmbito ser permeado por direitos e por ser um processo formativo do ser social, a categoria terá sua inserção na perspectiva do combate ás ameaças principais postas pelo capital principalmente de desarticulação da classe trabalhadora, que ocorre minuciosamente articulados no intuito do desmonte dos direitos sociais e de implementação das ideologias burguesas, incentivadas pelo contexto neoliberal.

O adentramento de assistentes sociais na formulação e acompanhamento dos programas do governo vem cada vez mais adensando discussões e experiências, articulando processos de 
Id on Line Revista Multidisciplinar e de Psicologia

Id on Line Multidisciplinary and Psycology Journal

reflexões e traçando estratégias para impulsionar a entrada do profissional de serviço social no campo das políticas públicas vislumbrando uma intervenção na luta pela garantia da educação como um direito social, em consonância com o que prescreve o projeto ético político profissional, onde se deve priorizar a dimensão política, se posicionando em favor da equidade e justiça social, na perspectiva da universalização, ampliando a consolidação da cidadania.

O profissional de Serviço Social adentra na luta pelo ingresso ao setor educacional não somente por mais um campo sócio-ocupacional, mas sim pela circunstância do campo estratégico que se efetiva a educação, tanto pela mesma, função de estar a serviço da inserção crítica, da decisão e transformação do mundo, a serviço da imobilidade da permanência das estruturas injustas, da acomodação dos seres humanos á realidade tida como intocável (FREIRE, 2000).

A tarefa imprescindível do assistente social inserido nesse espaço marcado pelo signo antagônico, de interesses divergentes e provedores de poder em formular novas formas de pensamento, e, portanto, contribuir para manter ou mudar de concepção de mundo, é no intuito da busca pelo reconhecimento da liberdade livre, plena autonomia e emancipação dos indivíduos sociais, nascendo assim á possibilidade de contribuição para a efetivação da formação dos autores despertar aos estudantes sua essência enquanto sujeito e não enquanto objeto de manobra de interesses do capital.

Refletir e propor trabalho social em rede constitui-se em um grande desafio, já que a tentativa de construir uma articulação entres as inúmeras políticas sociais é a fim de aprimorar a efetividade no atendimento e construir a ideia de articulação, conexão, vínculos, ações complementares, interdependência de serviços para garantir a integralidade da atenção aos segmentos sociais vulnerabilizados ou em situação de risco social e pessoal.

Na discussão que Iamamoto vem nos trazer o seu pensamento no que se refere o Serviço Social inserido nesse contexto:

O desafio é redescobrir alternativas e possibilidades para o trabalho profissional no cenário atual; traçar horizontes para a formulação de propostas que façam frente á questão social e que sejam solidárias com o modo de vida daqueles que a vivenciam, não só como vítimas, mas como sujeitos que lutam pela preservação e conquista de sua vida, da sua humanidade. Essa discussão é parte dos rumos perseguidos pelo trabalho profissional contemporâneo (IAMAMOTO, 1998, p. 75). 
Id on Line Revista Multidisciplinar e de Psicologia

Id on Line Multidisciplinary and Psycology Journal

Desvela-se as abstrações que mascaram as reais acepções dessa formação precarizada e acrítica acerca de uma realidade mais densa, entra em cena o profissional capaz de compreender essas relações de dominação. Onde somente especialistas embasados de trabalho enquanto marionete da garantia da produção e reprodução capitalista, no almejo de superação da ordem posta por esse modelo de sociedade.

Ora, a educação inserida na relação e reprodução das relações sociais, norteadas pela lógica da produção capitalista, impõe consequentemente uma racionalidade mercantilista a todos os níveis da educação, perpassando pela precarização como estratégia e a mercantilização como selecionador de quem vai poder adquiri-la.

Sendo que o tempo na escola no capitalismo serve para definir o tipo de trabalho a ser realizado. Quanto maior a escolarização, maior o reconhecimento da formação de base intelectual, enquanto ao trabalho manual é destinado um período de formação mais aligeirado que se realiza, em geral, no tempo da produção (SILVA, 2012, p.137).

Atenta-se para precisão de compreender a visão liberal tecnicista do governo federal, que prioriza a relação, com a iniciativa privada para a expansão da educação e com o aceleramento tecnicista da educação como opção para os filhos da classe trabalhadora, invés de garantir uma educação pública, gratuita e de qualidade, para todos, com o objetivo claro, de repartir as chances de uma educação integral para toda a população, subdividindo as possibilidades da classe trabalhadora em atingir a universidade, colocando como possível a educação profissionalizante, manobrando os jovens ao mercado precário de trabalho.

Todavia, a educação para o modo de produção capitalista é vista dentro da divisão sócio técnica do trabalho, dessa forma o papel do governo é oferecer uma educação fragmentada, ou seja, dividir as tarefas e não fazer o educando futuro trabalhador expandir suas habilidades e sim moldando os filhos da classe trabalhadora ao mercado de trabalho para serem explorados e alienados. Pois o capital desenvolve e aperfeiçoa essa mão de obra a serviço da sua promoção e de manutenção.

A educação apresenta-se como aparelho ideológico burguês através do ensino, principalmente em seu recorte profissionalizante, direcionando-se enquanto mola propulsora da rápida qualificação da mão de obra e para efetivação de lucros. Com isso a essência e a construção e a consolidação de uma sociedade baseada no princípio de exploração e desigualdade como explica BIAGINE (2004): 
As modalidades educacionais do Ensino Técnico vieram se desenvolvendo em sintonia com as necessidades impostas pelo capital em diferentes momentos históricos. O modo de produção capitalista teve, por muitas décadas, a sua força ideológica assegurada não somente pelo progresso da acumulação, mas também pela produção de um exercício industrial de reserva inteiramente a disposição do capital.

Este exercício de foi preconizado como o material humano necessário as alternativas necessidades de valorização capitalista. Assim, pode-se inferir que o Ensino Técnico possui, em sua essência histórica, a materialidade do propósito capital de formar massa de trabalho qualificados para ficar á disposição das necessidades da produção (pág.45).

Os profissionais da área de educação são desafiados cotidianamente a enfrentar as refrações de uma política educacional orientada por critérios do mercado, com o risco de reduzirem suas intervenções ao nível da reprodução das relações sociais de produção.

\begin{abstract}
É preciso desenvolver corretamente as aptidões dos homens que empregam esses meios (...) a direção coletiva da produção por toda a sociedade e o novo progresso da referida produção que disso resultará, necessitarão de homens novos e os formarão. A gestão coletiva da produção não pode ficar sob a responsabilidade tal com o é hoje; homens que dependem cada qual de um ramo determinado da produção, que estão aprisionados a ela e são explorados por ela, desenvolvem apenas um aspecto de suas aptidões á custa de todas as outras e só conhecem um ramo ou parte de algum ramo de toda a produção (MARX E ENGLENS, 94).
\end{abstract}

O que está em voga é bem diferente da intenção de dar possibilidades ao estudante conhecer e explorar os vários ramos da produção e suas capacidades lógicas, o interessante para esse modelo de produção é subdividir quem pensa e quem executa, e geralmente quem executa é vedado da chance de escolher pensar, por isso, existe um engessamento nas escolas públicas.

Para que se acredite que o possível dentro de sua condição social é estritamente ingressar em um curso técnico sem obter a real dimensão do que esses programas do governo, que aparentemente abre alternativa para aqueles que não tem opção, representam, aprisionando a classe exploradora a se conterem com o que está posto, apresentando-lhes uma forma unilateral da educação. 
Id on Line Revista Multidisciplinar e de Psicologia

Id on Line Multidisciplinary and Psycology Journal

\section{Considerações Finais}

Embora seja, a educação assolada pelo contexto neoliberal e utilizada como instrumento de manobra das massas, a mesma é aprovada pelo sistema como uma de congelamento das capacidades intelectuais da massa, impossibilitando o desenvolvimento da percepção e análise crítica, independente da máscara da realidade.

No ensino técnico são postas desafios no caminho que se direciona para a construção e reafirmação da ideologia imperialista que o capital introduz, principalmente nessa forma de ensino. O profissional da através de suas diretrizes atuaria para ensejar junto a essa classe subalternizada, o exercício crítico das suas designações profissionais para transformação societária, na mediação da construção da consciência política dos sujeitos que estão obrigatoriamente imersos nessa sociedade, viabilizando a capacidade de interpretar a sociedade em nas suas reais objetivações e disfunções.

O Serviço Social, no marco de sua renovação crítica e imerso nesse quadro de correlação de forças, em consonância com o seu Código de Ética torna-se palco privilegiado para a atuação que viabiliza a garantia de direitos e a efetivação da própria educação como um direito a todos os seres humanos, não somente como um acesso, mas no direcionamento de sua permanência de sua qualidade, aliado ao seu caráter libertador, consciente e questionador do sistema e das estruturas que geram as desigualdades sociais.

Para além das suas funções com o processo de formação do cidadão por meio da perspectiva que vem sendo construída como parte da luta e da organização social, os Assistentes Sociais embasados em seu referencial teórico-metodológico, permite que o profissional faça a crítica ontológica do cotidiano, da ordem burguesa e dos fundamentos opressores que persistem na realidade para que através do instrumento da educação e do acesso ao conhecimento o caminho seja clarificado para uma possível igualdade social.

Deve ser utilizada como organismo viabilizador de conquistas sócio, histórica e econômica e não com caráter repressor, manipulador além da superação de sua concreta monopolização. Nutrindo de maneira engessada e descaracterizada, o declínio intelectivo da maioria, negando a importância do contexto sócio-econômico e político que vivencia a sociedade. 
Sobretudo, compreendendo-a como parte constituinte e fundamental de um sistema, uma vez que é utilizada de acordo com interesses dominadores. Representa um reflexo do antifício adotado em um país e da conveniência desse país em cooptá-la, e representa ainda, um dos maiores e mais eficazes mecanismos de dominação coletiva dentro de um sistema, devorado somente para a mídia que aglutina uma camada maior que os que acessam a educação.

Lutar por uma educação em moldes diferentes do que é imposto hoje pelo direcionamento do neodesenvolvimentismo alicerçado pelo capital, lutar incansavelmente por uma educação que vislumbre a emancipação plena do sujeito, lutar, sobretudo, por um por projeto societário coletivo.

\section{Referências}

ALMEIDA, N.L. T. A educação como direito social e a inserção dos assistentes sociais em estabelecimentos educacionais. Cartilha _ O Serviço Social e a Política Pública de Educação. Minas Gerais, 2005.

BIAGINI, J. A materialidade e a discursividade da prática de ensinar no ambiente do Ensino Técnico, 2004. Tese. (Doutorado em educação) Universidade Católica de São Paulo, São Paulo, 2004. Disponível em:http://www.artigonal.com/educação-artigo/ensino-técnicoversus-ensino-superior. Acesso em: 10/09/2016.

BRASIL. Constituição da República Federativa do Brasil. Brasília: Imprensa, 1988.

BRASIL. Estatuto da Criança e do Adolescente no Brasil. Lei ${ }^{\circ}$ 8.069, de 13 de julho de 1990. Disponível em: http://portal.mec.gov.br/arquivos/pdf/lei8069. Acesso em: 10/09/2016.

BRASIL: Lei de Diretrizes e Bases da Educação Nacional. Lei n $^{\circ}$ 9.394/96, de 20 de dezembro de1996. Diário Oficial da União, Brasília, DF, 23 dez. 1996. Disponível em: portal. Mec.gov.br/arquivos/pdf/tvescola/lei/pdf. Acesso em 12/08/2016.

BRASIL. Lei de Diretrizes e Bases da Educação Básica. Lei n ${ }^{\circ} 9.394$ de 20 de dezembro de 1996. São Paulo: Ed. Esplanada.

BRASIL. Projeto de Lei $\mathbf{n}^{0} 004$ de 26 de Janeiro de 2009. Estabelece a criação do Serviço Social Escolar nas Escolas Públicas Municipais.

GUERRA, Yolanda. Instrumentalidade do processo de trabalho e Serviço Social. In: Revista Serviço Social e Sociedade n. 62. São Paulo: Cortez, 2000. 
Lei 8.662 de 13 de março de 1993. De regulamentação da profissão. Com alterações introduzidas pelas resoluções do CFESS.

FALEIROS, Vicente de Paula. A política social do estado capitalista: funções da previdência e da assistência social. São Paulo. Cortez, 1991.

FREIRE, Paulo. Educação como prática da liberdade. 5.Ed. Rio de Janeiro: Paz e Terra. 1975.

IAMAMOTO, Marilda Vilela; Carvalho, Raul de. Relações sociais e serviço social no Brasil: esboço de uma interpretação histórico-metodológica-34. Ed.- São Paulo, Cortez, 2011.

MARX, Karl, ENGELS, Friedrich. Crítica da educação e do ensino. São Paulo: Moraes, 1983.

PIANA, M.C. A construção do perfil do assistente social no cenário educacional. São Paulo. ED UNESP, 233 p.2009.

SILVA, Marcela Mary José da. Serviço Social na Educação: Teoria e Prática. Campinas, 2012.

Como citar este artigo (Formato ABNT):

LIMA, A. A.; OLIVEIRA, R.T.P. Educação Profissionalizante: Um Instrumento para Emancipação ou Alienação?. Id on Line Revista Multidisciplinar e de Psicologia, Janeiro de 2017, vol.10, n.33, p. 224-236. ISSN: 19811179 .

Recebido: 01/12/2016

Aceito: 02/12/2016 